\title{
Deposition of fluoride on enamel surfaces released from varnishes is limited to vicinity of fluoridation site
}

\author{
T. Attin • A. M. Lennon • M. Yakin • K. Becker • \\ W. Buchalla $\cdot$ R. Attin $\cdot$ A. Wiegand
}

Received: 6 February 2006 / Accepted: 21 September 2006 / Published online: 17 October 2006

(C) Springer-Verlag 2006

\begin{abstract}
The aim of the in-situ study was to determine fluoride uptake in non-fluoridated, demineralized enamel after application of fluoride varnishes on enamel samples located at various distances from the non-fluoridated samples. All enamel samples used were demineralized with acidic hydroxyethylcellulose before the experiment. Intraoral appliances were worn by ten volunteers in three series: (1, Mirafluorid, $0.15 \%$ F; 2, Duraphat, $2.3 \% \mathrm{~F}$ and 3, unfluoridated controls) of 6 days each. Each two enamel samples were prepared from 30 bovine incisors. One sample was used for the determination of baseline fluoride content (BFC); the other was treated according to the respective series and fixed in the intra-oral appliance for 6 days. Additionally, from 120 incisors, each four enamel samples were prepared (one for BFC). Three samples $(\mathrm{a}-\mathrm{c})$ were placed into each appliance at different sites: (a) directly neighboured to the fluoridated specimen (=next), (b) at $1-\mathrm{cm}$ distance $(=1 \mathrm{~cm})$ and (c) in the opposite buccal aspect of the appliance (=opposite). At these sites, new unfluoridated samples were placed at days 1, 3 and 5, which were left in place for 1 day. The volunteers brushed their teeth and the samples with fluoridated toothpaste twice per day. Both the $\mathrm{KOH}$-soluble and structurally bound fluoride were determined in all
\end{abstract}

T. Attin · A. M. Lennon • M. Yakin · K. Becker • W. Buchalla •

R. Attin $\cdot$ A. Wiegand

Department of Operative Dentistry,

Preventive Dentistry and Periodontology,

Georg-August-University Göttingen,

Göttingen, Germany

T. Attin $(\bowtie) \cdot$ A. M. Lennon $\cdot$ K. Becker $\cdot$ W. Buchalla

A. Wiegand

Clinic for Preventive Dentistry, Periodontology and Cariology,

University of Zürich,

Plattenstr. 11,

8032 Zurich, Switzerland

e-mail: thomas.attin@zzmk.unizh.ch samples to determine fluoride uptake and were statistically analyzed. One day, after fluoridation with Duraphat, $\mathrm{KOH}-$ soluble fluoride uptake in specimen a (=next) was significantly higher compared to the corresponding samples of both the control and Mirafluorid series, which in turn were not significantly different from each other. At all other sites and time points, fluoride uptake in the enamel samples were not different from controls for both fluoride varnishes. Within the first day after application, intra-oral-fluoride release from the tested fluoride varnish Duraphat leads to $\mathrm{KOH}$-soluble fluoride uptake only in enamel samples located in close vicinity to the fluoridation site.

Keywords Fluoride $\cdot$ Enamel $\cdot \mathrm{KOH}$-soluble $\cdot$ Transfer . Saliva

\section{Introduction}

It is well established that fluoride products play an important role in the prevention and remineralization of carious lesions. Topical fluoride applications in the form of varnishes and varnishes may lead to appreciable acquisition of fluoride on and in both enamel and dentin samples, which were directly treated with the agent $[4,6,14,21,25]$. Especially, the $\mathrm{KOH}$-soluble fluoride deposit on the surfaces of dental hard tissue might be elevated depending on the fluoride concentration and composition of the fluoride varnish applied. However, the $\mathrm{KOH}$-soluble fluoride deposit is continuously dissolved in the oral cavity due to the influence of saliva. This leads to a drastic reduction of the deposit within a period of about 1 week after application of the fluoride agent $[2,5,14]$.

After the use of fluoride-containing products, also, salivary fluoride levels are increased for a certain period of 
time depending on the concentration and application form used. This effect is important because fluoride levels above $0.04 \mathrm{ppm}$ in the surrounding solution of the dental hard tissue have been shown to be related to lower risk of caries progression in clinical studies $[16,17]$. The fluoride distribution in the oral cavity showed site-specific variations, which was exemplarily demonstrated by Weatherell at al. [24] after dissolving a fluoride tablet in the oral vestibulum. With oral fluoride-containing mouthrinses, salivary fluoride levels remain elevated for up to $12 \mathrm{~h}$ after application $[8,13,23,26]$. The use of fluoride mouthwashes twice daily leads to a sustained elevated fluoride level even between the daily applications [12]. Fluoride dentifrices can cause increase in salivary fluoride content for a period of about $60-90 \mathrm{~min}[3,11,26]$. Also, after application of fluoride varnishes onto tooth surfaces, salivary fluoride levels remain increased for up to $32 \mathrm{~h}[13,18,22]$.

The above-mentioned studies had made clear that fluoride-treated tooth surfaces and salivary fluoride levels are increased after administering local fluoride regimes. Besides these effects, it may be speculated that fluoride applications also lead to fluoride uptake at tooth surfaces that were not directly treated or covered with fluoridation agents such as varnishes. This fact could especially be important for demineralized surfaces, which were inaccessible to direct fluoride application such as inter-proximal areas. Due to toxicological and practical reasons, application of fluoride varnishes is mostly limited to some sites of the dentition. Therefore, the aim of the present study was to determine fluoride transfer from fluoride-varnished enamel surfaces to demineralized enamel surfaces located at various distances from the fluoridation site.

\section{Materials and methods}

Enamel samples

Enamel cylinders (4 $\mathrm{mm}$ in diameter) were prepared from the buccal surface of bovine incisors. The cylinders were ground flat and polished, thereby removing about $200-\mu \mathrm{m}$ depth of the enamel as controlled with a micrometer. Afterwards, all specimens were sterilized with gamma irradiation $(25 \mathrm{kGy})$. For rehydration, the sterilized samples were stored in synthetic saliva [1] for a minimum of 2 weeks. Then, all samples were demineralized with acidic hydroxyethylcellulose ( $\mathrm{pH} \mathrm{4.8,3}$ days).

According to this procedure, each two enamel samples were prepared from 30 bovine incisors and each four samples were gained from additional 120 incisors. One sample from each tooth was used for the determination of baseline fluoride content of the respective tooth. The remaining samples of the 30 bovine incisors were later treated according to series $1-3$. The remaining samples of the 120 bovine incisors were used for the determination of intra-oral fluoride transfer and acquisition.

Set-up of the study

The study was designed and conducted according to the guidelines of Good Clinical Practice. Ethical approval of the study was granted by the Ethics Committee of the University of Göttingen (2/9/01). Ten panellists (aged 21 to 29 years) participated in the study. They were all residents of Göttingen (fluoride content in domestic water: $<0.2 \mathrm{ppm} \mathrm{F}$ ). The subjects had been instructed to avoid fluoride uptake. The participants had a stimulated salivary fluoride rate within the normal range of $1.0-5.0 \mathrm{ml} / \mathrm{min}$. Further inclusion criteria were that they had at least 20 teeth, no faulty dental restorations, no glass ionomer fillings and no current dental caries activity.

Intra-oral, lower jaw appliances with two buccal aspects were worn by ten volunteers in three series of 6 days each. In each series, one enamel sample was placed for 6 days in one buccal aspect of the appliance after treatment according to the respective series (=central, fluoridated sample). With each five of the participants, the fluoridated samples were placed in the right buccal aspect; with the remaining subjects, the fluoridated samples were fixed in the left aspect of the appliance. A washout phase of 1 week elapsed between the three series.

Table 1 Ingredients and composition of the fluoride varnishes Mirafluorid ${ }^{\mathbb{E}}$ and Duraphat ${ }^{\mathbb{E}}$ according to manufacturers

\begin{tabular}{lll}
\hline & Mirafluorid $^{\circledR}$ & Duraphat $^{\circledR}$ \\
\hline Fluoride content & $0.12 \%$ & $2.26 \%$ \\
Fluoride form & Sodium fluoride & Sodium fluoride \\
& Cetylaminehydrofluoride & \\
& Bis(hydroxyethyl)-aminpropyl- & \\
& $N$-hydroxyethyl-octadecyl-amindihydrofluoride & Neutral \\
$\mathrm{pH}$ & 4.6 & alcohol (33.14\%) \\
Solvent & Solvent-free & Natural resins (colophonium, mastix, shellac) \\
Base & Water-soluble polymer & Wax, saccharine, flavour \\
Other ingredients & - & Colgate-Palmolive, Hamburg, Germany \\
Manufacturer & Hager \& Werken, Duisburg, Germany &
\end{tabular}


In series 1 and 2, $0.1 \mathrm{~g}$ of the fluoride varnish Mirafluorid ${ }^{\circledR}$ (1) or Duraphat ${ }^{\mathbb{B}}$ (2) was either applied on the central enamel sample (Table 1). Care was taken to avoid contamination of the remaining enamel samples of the intraoral appliances with the varnish applied. After application of the varnish, the intra-oral appliances were immediately inserted into the oral cavities. In series 3, the respective samples were not fluoridated with varnish and served as controls.

Each three unfluoridated samples were placed into each appliance at different sites $(\mathrm{a}-\mathrm{c})$ : (a) directly neighboured to the central, fluoridated specimen (=next), (b) at $1-\mathrm{cm}$ distance $(=1 \mathrm{~cm})$ and $(\mathrm{c})$ in the opposite buccal aspect of the appliance (=opposite). These three samples were replaced after 1, 3 and 5 days by new unfluoridated samples, which were removed after 1 day intra-oral exposition. Thus, each one sample was worn at the respective site for the following periods: days $0-1$, days $1-2$, days $3-4$ and days $5-6$. The central samples, which were fluoridated on day 0 , were not removed from the appliances before completion of the experiment.

The volunteers brushed their teeth and the samples with a pea-size amount of fluoridated toothpaste $(0.125 \%$ fluoride as amine fluoride) twice per day (elmex ${ }^{\circledR}$, GABA, Lörrach, Germany) during the experiment to simulate the common practice of using a fluoridated dentifrice and to follow the recommendations of the Ethical Committee, which did not allow detaining a fluoride dentifrice to the participants. They began to use the dentifrice 3 days before the start of the trial. After toothbrushing, the enamel samples in the appliances were carefully cleaned with ten brushing strokes using the toothbrush (impregnated with the remaining dentifrice slurry) that had been used for brushing of the teeth before. A minimum of $8 \mathrm{~h}$ elapsed between application of the respective varnish onto the central specimen and first brushing of the samples. During the experiment, the appliances were worn night and day except during meals, during which, they were stored in $0.9 \%$ saline.

\section{Fluoride analysis}

Immediately after removal from the intra-oral appliances, the enamel samples were cleaned with a soft toothbrush under running tap water and analyzed for $\mathrm{KOH}$-soluble and structurally bound fluoride. The fluoride was assayed by a specific fluoride electrode (Orion Research, Cambridge, USA). The structurally bound fluoride was determined in two successive layers of $30 \mu \mathrm{m}$ each. The layers were removed by means of a special grinding technique described in detail previously [15]. The amount of $\mathrm{KOH}$-soluble fluoride was determined by the method of Caslavska et al. [9]. The assays were prepared as described in those studies, resulting in a $0.9-\mathrm{ml}$ sample solution for $\mathrm{KOH}$-soluble fluoride and 3-ml solution for structurally bound fluoride determination, respectively. Also, fluoride content of the fluoridated samples was assessed after the experimental period.

\section{Statistics}

According to the manufacturer, sensitivity of the fluoride electrode is given as $1 \mu \mathrm{mol} / 1$ in a solution. Bioanalytical
Table 2 Percentages of measurements above detection limits $^{\mathrm{a}}$ for $\mathrm{KOH}$-soluble and structurally bound fluoride in two successive layers in enamel specimens worn in intra-oral appliances at different sites and for different periods (days $0-6$, days $0-1$, days $1-2$, days $3-4$ or days 5-6) after the application of either Duraphat, Mirafluorid or no fluoride varnish (control) on the central specimen on day 0

\begin{tabular}{|c|c|c|c|c|c|c|c|c|c|c|}
\hline \multirow[b]{2}{*}{ Period } & \multirow[b]{2}{*}{ Site } & \multicolumn{3}{|c|}{ 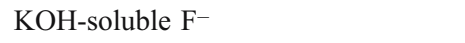 } & \multicolumn{3}{|c|}{ 1st Layer $(0-30 \mu \mathrm{m})$} & \multicolumn{3}{|c|}{ 2nd Layer $(31-60 \mu \mathrm{m})$} \\
\hline & & $\begin{array}{l}\text { Mirafluorid } \\
(\%)\end{array}$ & $\begin{array}{l}\text { Duraphat } \\
(\%)\end{array}$ & $\begin{array}{l}\text { Control } \\
(\%)\end{array}$ & $\begin{array}{l}\text { Mirafluorid } \\
(\%)\end{array}$ & $\begin{array}{l}\text { Duraphat } \\
(\%)\end{array}$ & $\begin{array}{l}\text { Control } \\
(\%)\end{array}$ & $\begin{array}{l}\text { Mirafluorid } \\
(\%)\end{array}$ & $\begin{array}{l}\text { Duraphat } \\
(\%)\end{array}$ & $\begin{array}{l}\text { Control } \\
(\%)\end{array}$ \\
\hline $0-6$ & Central & 90 & 100 & 0 & 10 & 100 & 10 & 10 & 100 & 0 \\
\hline $0-1$ & Next & 10 & 60 & 0 & 0 & 30 & 0 & 0 & 30 & 0 \\
\hline $0-1$ & $1 \mathrm{~cm}$ & 10 & 30 & 0 & 0 & 50 & 0 & 0 & 10 & 0 \\
\hline $0-1$ & Opposite & 0 & 0 & 0 & 0 & 10 & 0 & 0 & 0 & 0 \\
\hline $1-2$ & Next & 20 & 10 & 0 & 10 & 10 & 0 & 0 & 0 & 0 \\
\hline $1-2$ & $1 \mathrm{~cm}$ & 20 & 0 & 0 & 0 & 0 & 0 & 0 & 0 & 0 \\
\hline $1-2$ & Opposite & 10 & 0 & 0 & 0 & 0 & 0 & 0 & 0 & 0 \\
\hline $3-4$ & Next & 10 & 0 & 0 & 0 & 10 & 0 & 0 & 0 & 0 \\
\hline $3-4$ & $1 \mathrm{~cm}$ & 10 & 0 & 0 & 0 & 0 & 0 & 0 & 0 & 0 \\
\hline $3-4$ & Opposite & 10 & 0 & 0 & 0 & 0 & 0 & 0 & 0 & 0 \\
\hline $5-6$ & Next & 0 & 0 & 0 & 0 & 0 & 0 & 0 & 0 & 0 \\
\hline $5-6$ & $1 \mathrm{~cm}$ & 10 & 0 & 0 & 0 & 0 & 0 & 0 & 0 & 0 \\
\hline $5-6$ & Opposite & 0 & 0 & 0 & 0 & 0 & 0 & 0 & 0 & 0 \\
\hline
\end{tabular}

${ }^{\mathrm{a}}$ Detection limits $\left(\mathrm{KOH}\right.$-soluble $\mathrm{F}=0.544 \mu \mathrm{g} / \mathrm{cm}^{2}$, structurally bound fluoride $=604.8 \mu \mathrm{g} / \mathrm{cm}^{3}$ ) 
Table 3 Mean \pm standard deviation (median; minimum-maximum) of $\mathrm{KOH}$-soluble fluoride and structurally bound fluoride (in 1st and 2nd layer) given for the experimental groups with more than $50 \%$ of the respective measurements above detection limit

\begin{tabular}{|c|c|c|c|c|c|}
\hline \multirow[b]{2}{*}{ Period } & \multirow[b]{2}{*}{ Site } & \multicolumn{2}{|c|}{$\mathrm{KOH}$-soluble $\mathrm{F}^{-}\left(\mu \mathrm{g} / \mathrm{cm}^{2}\right)$} & \multirow{2}{*}{$\begin{array}{l}\text { 1st Layer }\left(\mu \mathrm{g} / \mathrm{cm}^{3}\right) \\
\text { Duraphat }\end{array}$} & \multirow{2}{*}{$\begin{array}{l}\text { 2nd Layer }\left(\mu \mathrm{g} / \mathrm{cm}^{3}\right) \\
\text { Duraphat }\end{array}$} \\
\hline & & Mirafluorid & Duraphat & & \\
\hline $0-6$ & Central & $\begin{array}{l}0.67 \pm 0.19^{\mathrm{a}} \\
(0.62 ; 0.54-1.1)\end{array}$ & $\begin{array}{l}8.38 \pm 3.18^{\mathrm{a}, \mathrm{c}} \\
(8.82 ; 3.65-14.5)\end{array}$ & $\begin{array}{l}2237 \pm 576^{\mathrm{b}} \\
(2,282 ; 1,233-3,315)\end{array}$ & $\begin{array}{l}1636 \pm 487^{\mathrm{b}} \\
(1,503 ; 1,110-2,646)\end{array}$ \\
\hline $0-1$ & Next & $-*$ & $\begin{array}{l}0.83 \pm 0.56^{\mathrm{c}} \\
(0.76 ; 0.16-2.12)\end{array}$ & $-*$ & $-*$ \\
\hline
\end{tabular}

*Less than $50 \%$ readings above detection limit

Significantly different values in the same line $\left({ }^{\mathrm{a}} \mathrm{KOH}\right.$-soluble $\mathrm{F}^{-},{ }^{\mathrm{b}}$ structurally bound $\left.\mathrm{F}^{-}\right)$or ${ }^{\mathrm{c}}$ column are marked.

guidelines recommend disregarding the measurements that are close to the sensitivity of an assessment method [20]. An international cooperation study [7] determining the lowest level of sensitivity for measurements with a fluoride electrode showed that measurements below $4 \mu \mathrm{mol} / \mathrm{l}$ (equivalent to $0.544 \mu \mathrm{g} / \mathrm{cm}^{2} \mathrm{KOH}$-soluble fluoride and 604.8 $\mu \mathrm{g} / \mathrm{cm}^{3}$ structurally bound fluoride) were unstable, not reproducible and showed high standard deviations and coefficients of variation $(>20 \%)$. Therefore, these readings were regarded as to be "below detection limit". Thus, fluoride uptake was not calculated by subtracting the baseline fluoride content of the respective tooth, which was below detection limit, from the measured value recorded for the specimen.

All groups were compared regarding their number of readings above detection limit using chi-square tests. For those groups, in which more than $50 \%$ of the readings were above the detection limit, discriminations were conducted using the rank-sum test according to Wilcoxon and MannWhitney. The level of significance was set at $P<0.05$.

\section{Results}

In Table 2, the percentages of fluoride measurements in the respective groups, which were above the detection limits, are given. It is obvious that most of the groups had more than $50 \%$ of their readings below the detection limit. Chi-square tests proved that the sample groups with more than $50 \%$ readings above detection limit were statistically significantly different from the remaining groups, which in turn did not differ significantly from each other.

In Table 3, KOH-soluble fluoride and structurally bound fluoride data of the experimental groups are given, for which more than $50 \%$ of the readings were above detection limit. As mentioned above, chi-square tests had proven that these values were statistically significantly different from baseline content and from the remaining groups. For the remaining groups, fluoride contents are not given because statistical data such as mean value or median are not reasonable to calculate for values, which are not reliably measurable by definition. Acquisition of $\mathrm{KOH}$-soluble fluoride was detectable in the central, fluoridated samples of both groups, Mirafluorid and Duraphat, with the latter once accumulating statistically significantly more $\mathrm{KOH}-$ soluble fluoride $(P=0.00015)$. The central, fluoridated Duraphat samples also showed significant uptake of structurally bound fluoride in both enamel layers with significantly higher uptake in the first layer compared to the second one $(P=0.02836)$. One day after fluoridation, the samples located next to the Duraphat-varnished central specimens also accumulated measurable amounts of $\mathrm{KOH}-$ soluble fluoride. The $\mathrm{KOH}$-soluble precipitate on these samples was statistically significantly less pronounced compared to the central specimens $(P=0.00015)$. The samples located next to the Duraphat-treated showed measurable $\mathrm{KOH}$-soluble fluoride acquisition at days $0-1$. They, therefore, differed significantly from both the control and Mirafluorid series, which did not show measurable fluoride acquisition at this time point and were, in turn, not significantly different from each other. At all other sites and time points, fluoride uptake in the enamel samples was not different from controls for both fluoride varnishes.

\section{Discussion}

As stated in "Introduction", several investigations had demonstrated that intra-orally applied fluoride regimes may cause fluoride release into saliva. In a previous study, Dijkman et al. [10] had demonstrated that no measurable fluoride enrichment could be detected in untreated sound enamel controls located in a distance of $3 \mathrm{~mm}$ from fluoride varnish-treated samples after a period of 1 week. The present study made clear that within the first day after application the highly concentrated fluoride varnish Duraphat $\mathrm{KOH}-$ soluble fluoride deposition in close vicinity to the fluoridation occurs. However, in consistence with the investigation by Dijkman et al. [10], no measurable fluoride transfer could be revealed after the first day. Although, when interpreting the 
results of the present study, it should be noted that a more sensitive method for fluoride determination might have shown slightly different results.

In the present study, no fluoride acquisition could be detected in samples located at a distance of $1 \mathrm{~cm}$ from the fluoridated site or fixed in the opposite vestibulum of the participants. This means that fluoride transfer via saliva was strictly limited to the close neighbourhood of the fluoridation site. This finding corresponds to a previous study, which demonstrated that significant elevation of salivary fluoride concentrations is more or less restricted to the fluoridation site [24].

With exception for the samples directly treated with Duraphat, no measurable acquisition of structurally bound fluoride was observed in any other sample group. In a previous study, application of Mirafluorid did not also result in uptake of structurally bound fluoride [2]. However, also the samples which were located next to the specimens treated with Duraphat for 1 day and which showed a $\mathrm{KOH}$-soluble fluoride deposit did not show increase of structurally bound fluoride. This finding could be explained by the fact that formation of structurally bound fluoride is a time-dependent process during which some of the $\mathrm{KOH}-$ soluble deposit is dissolved, allowing fluoride to diffuse into the underlying enamel and to be structurally incorporated into the enamel crystallites [19]. However, in these samples, structurally bound fluoride was assessed already 1 day after insertion into the appliance. It might be speculated that with longer exposition in the oral cavity, structurally bound fluoride might have been formed by dissolution from the $\mathrm{KOH}$-soluble fluoride deposit.

In the present study, demineralized enamel specimens were used for assessing fluoride acquisition. Recent studies had proven that fluoridation measures lead to significantly higher uptake of fluoride in demineralized samples as compared to sound enamel [1]. It could, therefore, be assumed that fluoride acquisition of sound enamel surfaces due to fluoride transfer in the oral cavity might be actually more limited as compared to the present results.

Under clinical conditions, a varnish is often applied onto more sites, which might elevate salivary fluoride to a presumably higher extent as in the present study, where the varnishes were applied to a single site only.

Due to the results of the present study, it could be concluded that within the first day after application, intraoral fluoride release from the tested fluoride varnish Duraphat leads to $\mathrm{KOH}$-soluble fluoride uptake only in demineralized enamel samples, which are located in close vicinity to the fluoridation site. Owing to the negligible transfer of fluoride from the varnish to more remote sites, this finding means, for the clinical situation, that all sites in the oral cavity requiring fluoridation have to be directly treated with the varnish.

\section{References}

1. Attin T, Dumont B, Buchalla W (2000) Fluoride uptake in caries, eroded and sound enamel after application of a $2000 \mathrm{ppm}$ fluoride solution. Dtsch Zahnärztl Z 55:455-460 (in German)

2. Attin T, Grieme R, Paque F, Hannig C, Buchalla W, Attin R (2005) Enamel fluoride uptake of a novel water-based fluoride varnish. Arch Oral Biol 50:317-322

3. Attin T, Hellwig E (1996) Salivary fluoride content after toothbrushing with a sodium fluoride and an amine fluoride dentifrice followed by different mouthrinsing procedures. J Clin Dent 7:6-8

4. Attin T, Schaller HG, Hellwig E (1997) Fluoride uptake in dentin with and without simulating dentinal fluid flow. Clin Oral Investig $1: 125-130$

5. Belser U, Sporri S, Muhlemann HR (1975) Uptake and retention of fluoride by intact and etched enamel. Helv Odontol Acta 19: 69-71

6. Buchalla W, Attin T, Schulte-Monting J, Hellwig E (2002) Fluoride uptake, retention, and remineralization efficacy of a highly concentrated fluoride solution on enamel lesions in situ. J Dent Res 81:329-333

7. Buchalla W, Becker K, Neurath H, Buijs MJ, Imfeld T, Lussi A, Stösser L, ten Cate JM, Attin T (2006) Detection limit of fluoridesensitive electrode reconsidered by multi-center study. Caries Res 40:303 (abstract)

8. Campus G, Lallai MR, Carboni R (2003) Fluoride concentration in saliva after use of oral hygiene products. Caries Res 37:66-70

9. Caslavska V, Moreno EC, Brudevold F (1975) Determination of the calcium fluoride formed from in vitro exposure of human enamel to fluoride solutions. Arch Oral Biol 20:333-339

10. Dijkman AG, de Boer P, Arends J (1983) In vivo investigation on the fluoride content in and on human enamel after topical applications. Caries Res 17:392-402

11. Duckworth RM, Morgan SN (1991) Oral fluoride retention after use of fluoride dentifrices. Caries Res 25:123-129

12. Duckworth RM, Morgan SN, Murray AM (1987) Fluoride in saliva and plaque following use of fluoride-containing mouthwashes. J Dent Res 66:1730-1734

13. Eakle WS, Featherstone JD, Weintraub JA, Shain SG, Gansky SA (2004) Salivary fluoride levels following application of fluoride varnish or fluoride rinse. Community Dent Oral Epidemiol 32: 462-469

14. Hellwig E (1992) Fluoride retention in dentin after topical application of aminefluoride. J Dent Res 71:1558-1560

15. Hellwig E, Klimek J, Albert G (1989) In-vivo retention angelagerten und festgebundenen Fluorids in demineralisertem Zahnschmelz. Dtsch Zahnärztl Z 44:173-176

16. Leverett DH, Featherstone JD, Proskin HM, Adair SM, Eisenberg AD, Mundorff-Shrestha SA, Shields CP, Shaffer CL, Billings RJ (1993) Caries risk assessment by a cross-sectional discrimination model. J Dent Res 72:529-537

17. Leverett DH, Proskin HM, Featherstone JD, Adair SM, Eisenberg AD, Mundorff-Shrestha SA, Shields CP, Shaffer CL, Billings RJ (1993) Caries risk assessment in a longitudinal discrimination study. J Dent Res 72:538-543

18. Petersson LG, Ludvigsson N, Ullbro C, Gleerup A, Koch G (1987) Fluoride clearance of whole saliva in young school children after topical application. Swed Dent J 11:95-101

19. Rølla G, Saxegaard E (1990) Critical evaluation of the composition and use of topical fluorides, with emphasis on the role of calcium fluoride in caries inhibition. J Dent Res 69:780-785

20. Shah VP, Midha KK, Findlay JW, Hill HM, Hulse JD, McGilveray IJ, McKay G, Miller KJ, Patnaik RN, Powell ML, Tonelli A, Viswanathan CT, Yacobi A (2000) Bioanalytical method valida- 
tion - a revisit with a decade of progress. Pharm Res 17:15511557

21. Ten CJM (1997) Review on fluoride, with special emphasis on calcium fluoride mechanisms in caries prevention. Eur J Oral Sci 105:461-465

22. Twetman S, Skold-Larsson K, Modeer T (1999) Fluoride concentration in whole saliva and separate gland secretions after topical treatment with three different fluoride varnishes. Acta Odontol Scand 57:263-266

23. Vogel GL, Carey CM, Ekstrand J (1992) Distribution of fluoride in saliva and plaque fluid after a $0.048 \mathrm{~mol} / \mathrm{L} \mathrm{NaF}$ rinse. J Dent Res 71:1553-1557
24. Weatherell JA, Robinson C, Nattress BR (1989) Site-specific variations in the concentrations of substances in the mouth. $\mathrm{Br}$ Dent J 167:289-292

25. Wiegand A, Krieger C, Attin R, Hellwig E, Attin T (2005) Fluoride uptake and resistance to further demineralisation of demineralised enamel after application of differently concentrated acidulated sodium fluoride gels. Clin Oral Investig 9:52-57

26. Zero DT, Fu J, Espeland MA, Featherstone JD (1988) Comparison of fluoride concentrations in unstimulated whole saliva following the use of a fluoride dentifrice and a fluoride rinse. J Dent Res 67:1257-1262 